\title{
The Most Common Athletic Injuries among Swimmers: The Case for University Students in Jordan
}

\author{
Ibrahim M. Harafsheh"1, Faleh S. Abu-Eid² \\ ${ }^{1}$ Physical Education and Sport Sciences Faculty, The Hashemite University, Zarqa, Jordan \\ ${ }^{2}$ Deanship of Students Affairs, The Hashemite University, Zarqa, Jordan \\ Email: Iharafsheh@yahoo.com
}

Received 18 March 2016; accepted 1 May 2016; published 4 May 2016

Copyright (C) 2016 by authors and Scientific Research Publishing Inc.

This work is licensed under the Creative Commons Attribution International License (CC BY). http://creativecommons.org/licenses/by/4.0/

(c) (i) Open Access

\begin{abstract}
This study aims to identify the most athletic common injuries among a sample of $\mathbf{1 2 5}$ swimmers from the college of Physical Education and Sport Sciences at the Hashemite University. The results of the study indicate that the most common injuries among swimmers are the injuries of muscle tension in the areas of the leg and wrist. However, the neck and elbow areas are less vulnerable to injury among swimmers. The researchers recommend that swimmers should focus on the importance of good warming-up before swimming training in addition to taking into account the factors of safety inside and around the swimming pool.
\end{abstract}

\section{Keywords}

Athletes, Injuries, Swimmers, University Students, Jordan

\section{Introduction}

Swimming is an interesting kind of sport and useful activity for the human health and the muscles' development and flexibility of joints to shape the healthy body. Swimming is organizing the process of breath and contributing to activating the circulating system, it also supports the process of digestion. It contributes to improving all the body muscles especially the muscles of the spine as well it removes some of body defects such as back curvature, bowleg and rickets. Therefore swimming is the complete sport which no sport alike in shaping the healthy body (Hussein, 2000). Swimming is an important activity for both females and males at all ages for its healthy, entertaining, remedial and psychological benefits as the companion Omar Ibn Alkhattab (God please him) said: "learn your children shooting, swimming and horse riding” (Al Khouli, 1995). 
It is common that swimming is the less sport causing athletic injuries, but in fact some swimmers expose to different athletic injuries during training or championships. Therefore, this sport requires a good body preparation inside and outside the water to decrease the possibility of exposing the swimmer to injuries. Mohammad (2004) mentioned that athletic injury was exposing the body tissues to an outside and inside effects that led to anatomical and physiological changes in the area of injury, leading to disability of the function of that tissue. Darwish (1985) assured that the swimmer must be away from practicing the activity for a specific period determined according to the area and the severity of the injury. And he refers to that the injury is considered as an obstacle for players during their training and competitions that decrease their skillful performance and it may be a reason of leaving this sport early.

In practicing swimming there is a possibility of athletic injuries during training or warming-up before training, such as, falling the swimmer down around the pool or inside it by indirect gliding by water. And this may lead to athletic injury in lower back especially if there is a muscle tension in that area. And these situations may happen in chest stroke and butterfly swimming. In addition to lower back injuries, some of injuries may affect the upper area of the spine and neck because of over tension in this area, and also the continuous extension movement of the head during these two kinds of swimming may affect neck injury. Some wrong movements and falling down on the ground by the swimmer may lead to joint dislocation of shoulders. Some skills of swimming require wide movement place which causes high tension strength of tissues and ligaments in this area and exposes them to ruptures (Hamill \& Knutzen, 2003).

\section{Theoretical Framework}

A study by (Knobloch et al., 2008) conducted on a sample of 341 swimmers at the ages between (11 - 19) years old; wherein the results of this study referred that the most athletic injuries among swimmers are the upper limbs infects with $11 \%$ percentage, while the trunk infects with $8 \%$ percentage and the lower limbs of $6 \%$.

Maghayrah (2008) conducted a study to recognize the most common injuries among fencing players in Jordan according to the variable of training age. The sample of the study consisted of 39 players who attending Jordan Fencing Federation; the conclusions of the study showed the most common athletic injuries among them are bruises and abrasions. And the conclusions showed as well that the main cause of these injuries is the lack of good warming up.

Another study by Majli \& Ismaiel (2007), titled the athletic injuries among basketball players in Jordan, conducted on a sample of 112 players and resulted that the most common injury among them is sprains with the percentage of $20 \%$. And the most areas vulnerable to the injuries are the ankle, knee joint and elbow joint.

\subsection{The Problem of the Study}

Studies refer to that the injuries increase with whom has wrong techniques. Wherein the right way to prevent injuries is the right performance of the movement generally, and any wrong performance leads to disability of the muscular tissues in the body; this is what mentioned by Mohammad (2004). So the researchers tried to show the common injuries of swimmers and the areas vulnerable to these injuries by this study.

\subsection{Objectives of the Study}

1). This study aims at recognizing the most common injuries in swimming

2). It aims as well to recognize the more areas vulnerable to the injuries.

\subsection{Questions of the Study}

1). What are the most common injuries among swimmers?

2). What are the most areas vulnerable to the injuries among swimmers?

\subsection{Fields of the Study}

Human Field: this study limited on the students of college of Physical Education and Sport Sciences in Hashemite University who have finished all the requirements of swimming and swimming training and management courses. 
Time Field: this study conducted in the period between 8/12-12/12/2013.

\section{Methodology}

The researchers used the descriptive methodology by survey ways in because of its appropriateness to the nature of the study.

\subsection{Study Population}

The study population consisted of the students of Physical Education and Sport Sciences in Hashemite University who have finished all the requirements of swimming and swimming training and management courses and they were 93 male students and 37 females. These students had experience with swimming.

\subsection{Study Sample}

The study sample is the field of the study; 125 students depending on the variables of education as showed in the Table 1.

\subsection{Data Collection}

A particular questionnaire prepared by Majli \& Atteyat (2004) is used for athletic injuries. It is already used in Jordanian environment and it is trustworthy. For sureness, the researchers counted the reliability through application and reapplication one week later among five students out from the sample of the study. The correlation coefficient reached (0.86).

\section{Results and Discussion}

In the lights of objectives and questions of the study, the researchers conducted statistical analysis for the collected data by the individuals of study sample to recognize the most injuries vulnerable to swimmers. Below are the results:

\subsection{Results and Discussion Pertain to First Question}

What are the most common injuries among swimmers? To answer this question, Table 2 shows the answers depending on education variables:

From table number 2 it is obvious that muscular tension injury is the highest incident according to repetition, as the total of injuries for males is 60 injuries with $25.2 \%$ from the whole total of injuries which is 238 injuries, The next one is muscular rupture with repetition of 40 injuries and 16.8 percentage, Then sprains with total of 36 injuries and $15.1 \%$ percentage, then bruises with 20 injuries and $8.4 \%$ percentage, the next one is dislocation injury with 17 injuries an $7.1 \%$ percentage, then fractures injuries with 8 repetition injuries and $3.4 \%$ percentage and finally other injuries with repetition of 4 injuries and $1.7 \%$ percentage.

For females, the first rank injury is muscular tension with repetition of 13 injuries and 5.5\% percentage, then sprains with 12 repetitions and 5\% percentage, then bruises with 20 repetitions and $8.4 \%$ percentage, then dislocation repetitions by 17 injuries and $7.1 \%$ percentage, then fractures with 8 injuries and 3.4\% percentage and finally other injuries with 4 repetitions and $1.7 \%$ percentage.

According to the previous show we recognize that the most common athletic injuries among swimmers; females and males are the muscular tension injury. As swimming is one of sports which require a very good

Table 1. Distribution the study sample depending on education variables $\mathrm{N}=125$.

\begin{tabular}{|c|c|c|c|}
\hline Variable & & Number of Students & Percentage \\
\hline \multirow{2}{*}{ Gender } & Male & 90 & $72 \%$ \\
\hline & Female & 35 & $28 \%$ \\
\hline \multirow{2}{*}{ Education level } & First + second year & 57 & $45.6 \%$ \\
\hline & Third + fourth year & 68 & $54.4 \%$ \\
\hline
\end{tabular}


Table 2. The most common injuries among swimmers depending on gender variable.

\begin{tabular}{|c|c|c|c|c|}
\hline Number & Injury Type & Gender & Repetition & Percentage \\
\hline \multirow{2}{*}{1} & \multirow{2}{*}{ Sprain } & male & 36 & 15.1 \\
\hline & & female & 12 & 5.0 \\
\hline \multirow{2}{*}{2} & \multirow{2}{*}{ Rupture } & male & 40 & 16.8 \\
\hline & & female & 9 & 3.8 \\
\hline \multirow{2}{*}{3} & \multirow{2}{*}{ Bruises } & male & 20 & 8.4 \\
\hline & & female & 11 & 4.6 \\
\hline \multirow{2}{*}{4} & \multirow{2}{*}{ Muscular tension } & male & 60 & 25.2 \\
\hline & & female & 13 & 5.5 \\
\hline \multirow{2}{*}{5} & \multirow{2}{*}{ Fractures } & male & 8 & 3.4 \\
\hline & & female & 3 & 1.3 \\
\hline \multirow{2}{*}{6} & \multirow{2}{*}{ Dislocation } & male & 17 & 7.1 \\
\hline & & female & 3 & 1.3 \\
\hline \multirow{2}{*}{7} & \multirow{2}{*}{ Other injuries } & male & 4 & 1.7 \\
\hline & & female & 2 & 0.8 \\
\hline Total injuries & 238 & 100 & & \\
\hline
\end{tabular}

warming-up before practice in order to raise the muscles temperature and stimulate it to the activity. The reasons behind this injury are many such as not warming up before practicing, tiredness or coolness of water regardless they are males or females, this is what mentioned by Rizq (2003) \& Micheli et al. (2001) and they confirmed as well that the performance of lengthiness and warming-up exercises is necessary for all the body joints in order to raise movement strength and decrease athletic injuries.

From Table 3 we observe that the most common injuries depending on education level variable are as following:

First: students of first and second year are exposed to muscular tension injury more than other injuries as it showed above the repetition is 51 and the percentage is $21.4 \%$, the next injury is sprains with 37 repetitions and $15.5 \%$ percentage, then rupture injury which is repeated with 30 injuries and $12.6 \%$ percentage, the following injury is bruises with 20 repetitions and 8.4\% percentage, then dislocation injuries with 18 repetitions and $7.6 \%$ percentage, the following injury is fractures ones with 7 repeated injuries and 3\% and finally the other injuries with 5 repetitions and $2.1 \%$ percentage.

Second: third and fourth year students are exposed to muscular tension injuries with repetitions of 21 injuries and 8.8\%, then rupture with 19 injuries and 8\% percentage, then sprains with 11 repetitions and 4.6\% percentage, then bruises with 11 repetitions and 4.6\% percentage, then fractures with 4 injuries and 1.7\% percentage and dislocation injuries repeated 2 times with $0.8 \%$ percentage and finally the other injuries with 2 repetitions as well with $0.8 \%$ percentage.

Concluded from what is mentioned above that the of first and second year students exposed to 168 injuries from the total of whole injuries which counted 238 injuries with the percentage of $71 \%$. Whereas third and fourth year students exposed to 70 injuries with $29 \%$ percentage. This result is suitable and expected according to the researchers because the first and second year students are less aware about the athletic injuries and its preventions. While it is expected that third and fourth year students have finished all the practical courses and requirements to be able to recognize the athletic injuries and how to avoid such cases; this is mentioned by Riyad (1986) as the general fitness of the player increases, his skills, muscular strength and flexibility increase as well leading to decrease the cases of athletic injuries.

\subsection{Results and Discussion Pertain to Second Question}

What are the most areas vulnerable to the injuries among swimmers? Table 4 answers this question according to different variables. 
Table 3. The most common injuries among swimmers depending on education level variable.

\begin{tabular}{|c|c|c|c|c|c|}
\hline Number & Type of Injury & First \& Second Year & Percentage & Third \& Fourth Year & Percentage \\
\hline 1 & Sprain & 37 & 15.5 & 11 & 4.6 \\
\hline 2 & Rupture & 30 & 12.6 & 19 & 8 \\
\hline 3 & Bruises & 20 & 8.4 & 11 & 4.6 \\
\hline 4 & Muscular tension & 51 & 21.4 & 21 & 8.8 \\
\hline 5 & Fractures & 7 & 3 & 4 & 1.7 \\
\hline 6 & Dislocation & 18 & 7.6 & 2 & 0.8 \\
\hline 7 & Other injuries & 5 & 2.1 & 2 & 0.8 \\
\hline \multicolumn{2}{|r|}{ Total } & \multicolumn{2}{|l|}{168} & \multicolumn{2}{|l|}{70} \\
\hline \multicolumn{2}{|c|}{ Percentage $100 \%$} & \multicolumn{2}{|l|}{$71 \%$} & \multicolumn{2}{|l|}{$29 \%$} \\
\hline
\end{tabular}

Table 4. The areas vulnerable to athletic injuries, the repetition and the percentage among swimmers according to gender variable.

\begin{tabular}{|c|c|c|c|c|c|c|}
\hline Number & Injury Area & Males & Percent of Males & Females & Percent of Females & Total of injuries \\
\hline 1 & The head & 12 & $5 \%$ & 5 & $2.1 \%$ & 17 \\
\hline 2 & The neck & 2 & $0.8 \%$ & 1 & $0.4 \%$ & 3 \\
\hline 3 & The shoulder & 32 & $13.5 \%$ & 15 & $6.3 \%$ & 47 \\
\hline 4 & Collarbone & 2 & $0.8 \%$ & 2 & $0.8 \%$ & 4 \\
\hline 5 & The elbow & 5 & $2.1 \%$ & 1 & $0.4 \%$ & 6 \\
\hline 6 & The wrist & 20 & $8.4 \%$ & 9 & $3.8 \%$ & 29 \\
\hline 7 & The pelvis & 15 & $6.3 \%$ & 16 & $6.8 \%$ & 31 \\
\hline 8 & The knee & 15 & $6.3 \%$ & 7 & $2.9 \%$ & 22 \\
\hline 9 & The leg & 35 & $14.8 \%$ & 19 & $8.1 \%$ & 54 \\
\hline 0 & The ankle & 12 & $5 \%$ & 2 & $0.8 \%$ & 14 \\
\hline 11 & Other injuries & 7 & $2.9 \%$ & 4 & $1.7 \%$ & 11 \\
\hline \multicolumn{2}{|r|}{ Total } & 157 & $65.9 \%$ & 81 & $34.1 \%$ & 238 \\
\hline
\end{tabular}

We observe from Table 4 the following:

First: the most area exposed to injuries according to males is the leg with repetitions of 35 injuries and percentage of $14.8 \%$, after the leg, the shoulder is exposed to injuries with 32 repetitions and $13.5 \%$ percentage, then the wrist with 20 injuries and 8.4\% percentage, the pelvis and knee areas with 15 injuries and $6.3 \%$ percentage, the next area is the head and ankle with 12 injuries and 5\% percentage and finally the neck and collarbone with 2 injuries and $0.8 \%$ percentage.

Second: the most area exposed to injuries according to females is the leg with 19 injuries and $8.1 \%$ percentage, then the pelvis area with 16 injuries and $6.8 \%$ percentage, then the shoulder with 15 injuries and $6.3 \%$ percentage, the following area that exposed to the injuries is the wrist area with 9 injuries and $3.8 \%$ percentage, then the knee with 7 repetitions of injuries and $2.9 \%$ percentage, then the last one is the neck and elbow with 1 injury to each one of them and with the percentage of $0.4 \%$.

The leg area is the most vulnerable area to injuries for both males and females, and this is an expected result since during the process of swimming, the swimmer moves and hit the legs in a way that leads to muscular tension whether because of being afraid, confused or because of the coolness of water or tiredness. According to the importance of feet movement in swimming, Ja'far (1988) mentioned that the hits of legs is the most essential skill in swimming wherein the swimmer raise the weight of the body from the gravitation and reach it to the horizontal position with the surface of the water in addition to their importance of supporting the swimmer by a push strength to go ahead during swimming.

From Table 5 we notice the following:

First: the students of first and second year exposed to leg injuries more than other areas wherein they have 46 
Table 5. The areas vulnerable to athletic injuries, the repetition and the percentage among swimmers according to education level variable.

\begin{tabular}{ccccccc}
\hline Number & Area of the Injury & First \& Second Year & Percentage & Third \& Fourth Year & Percentage & Total of Injuries \\
\hline 1 & The head & 11 & $4.6 \%$ & 6 & $2.5 \%$ & 17 \\
2 & The neck & 2 & $0.8 \%$ & 1 & $0.4 \%$ & 3 \\
3 & The shoulder & 35 & $14.7 \%$ & 12 & $5 \%$ & 47 \\
4 & Collarbone & 2 & $0.8 \%$ & 2 & $0.8 \%$ & 4 \\
5 & The elbow & 4 & $1.7 \%$ & 2 & $0.8 \%$ & 6 \\
6 & The wrist & 16 & $6.7 \%$ & $9.4 \%$ & 29 \\
7 & The Pelvis & 22 & $9.3 \%$ & $4.8 \%$ & 31 \\
8 & The knee & 18 & $7.6 \%$ & 8 & $1.7 \%$ & 22 \\
9 & The leg & 46 & $19.3 \%$ & $5.2 \%$ & 54 \\
10 & The ankle & 9 & $3.8 \%$ & 5 & $2.1 \%$ & 14 \\
& Other injuries & 6 & $2.5 \%$ & 67 & $2.1 \%$ & 11 \\
\hline
\end{tabular}

injuries with percentage of $19.3 \%$, the next vulnerable area to athletic injuries among the first and second year students is the shoulder with 35 injuries and $14.7 \%$ percentage, then the pelvis with 22 injuries and $9.3 \%$ percentage, the next area is the knee with 18 injuries and $7.6 \%$ percentage, then the wrist with 16 injuries and $6.7 \%$ percentage, then the head area with 11 injuries an $4.6 \%$ percentage, the ankle area with 9 injuries and 3.8\% and finally neck and collarbone areas with 2 injuries to each of them and $0.8 \%$ percentage. The reason of these results according to the researchers is that the students of first year have no high fitness or muscular strength to be able to do the exercises in a high qualification in comparison with their level at the third and fourth year.

Second: third and fourth year students are more vulnerable to the injuries in wrist area more than other areas with repetitions of 13 injuries and 5.4\% percentage, then the shoulder area with 12 injuries and $5 \%$ percentage, then the pelvis area with 9 injuries and 3.8\% percentage, then the leg with 8 injuries and $3.2 \%$ percentage and the head with 6 injuries and 2.5\% percentage and finally the neck area with 1 injury and $0.4 \%$ percentage.

The reason behind these results, according to the researchers, is avoidance of a good warming-up before swimming which contributes to increase the possibility of athletic injuries. Mohammad (2004) mentioned that the most essential reason behind the athletic injuries is the weakness of fitness because it affects the muscles, tissues, joints and the whole strength of the body negatively which makes the player disable from doing any exercise without tiredness. If the movement of legs and wrists increases, the rotational power on shoulder and pelvis increases as well. Bartlett (2003) referred that if the rotational powers increase over the joint, the possibility of getting athletic injuries increase.

\section{Conclusions}

In this study the researchers conclude the following:

- Muscular tension injury is the highest incident according to the repetitions of injuries among the swimmers and this is depending on gender and educational level variables.

- The leg area is the most vulnerable area to the athletic injuries whether the swimmer is male or female.

- The leg area is the most vulnerable area to the athletic injuries for the first and second year students.

- The wrist area is the most vulnerable area to the athletic injuries for the third and fourth students.

- The neck and the collarbone areas are the least vulnerable area to the athletic injuries among swimmers whether they are males, females or the first and second year students.

- The neck and the elbow areas are the least vulnerable area to the athletic injuries among females.

-The neck area is the least vulnerable area to athletic injuries for third and fourth year students.

\section{Recommendations}

According to the conclusions of this study, the researchers recommend the importance of a good warming-up 
before swimming. Warming-up may include jagging for at least 15 minutes and undergoing stretching techniques available for swimmers, also, taking into account the factors of safety inside and around the swimming pool. Moreover, the researchers recommend that swimmers should avoid practicing of swimming without the trainer or the qualified rescuer. Finally, it is recommended that swimmers should be aware of athletic injuries and the ways of its prevention.

\section{References}

Al Khouli, A. A. (1995). Islamic Civilization and Sport. Cairo: Dar el Fikr.

Bartlett, R. (2003). Introduction to Sport Biomechanics ( $5^{\text {th }}$ ed.). London: Spon Press.

Hamill, J., \& Knutzen, M. K. (2003). Biomechanical Basis of Human Movement (2 ${ }^{\text {nd }}$ ed.). Philadelphia, PA: Lippinott Williams \& Wikins, United State of America.

Hussein, Q. H. (2000). The Principles and Bases of Swimming. Amman: Dar el Fikr for Printing and Publishing.

Knobloch, K., Yoon, U., \& Kraemer, R. (2008). Breaststroke Event Dominate among Knee Overuse Injuries in Elite Swimming Athletes. Sportverletz Sportshaden, 22, 213-219. http://dx.doi.org/10.1055/s-2008-1027987

Majli, M., \& Atiyat, K. (2004). Analytical Study for Athletic Injuries among Fencing Players in Jordan. Physical Education Researches, 27, 15.

Majli, M., \& Ismaiel, M. (2007). Athletic Injuries among Basketball Players in Jordan. The First Scientific Conference, The Role of Departments of Physical Education's Colleges in Developing Arabian Sport. Amman: Physical Education College, Jordan University.

Micheli, L. S., Angela, B., \& Norbert, R. C. (2001). International Federation of Sport Medicine; Team Physician Manual. Hong Kong: Lippinott Williams \& Wikins Asia Ltd.

Mohammad, S. K. (2004). Athletic Injuries. Baghdad: Iraqi Sport Academy.

Riyad, O. (1986). Athletic Injuries by Images. Riyadh: Saudi Arabian Federation for Sports Medicine.

Rizq, S. A. (2003). Encyclopedia for Swimming Sport. Ajman: Al-Amiri Print. 